\title{
Analysis of adnexal masses requiring reoperation following hysterectomy
}

Karthiga Prabhu J.*, Ramya Sundaram, Valli V., Muthulakshmi M.

Department of Obstetrics and Gynaecology, SRM Medical College Hospital \& Research Centre, Potheri, Tamilnadu, India

Received: 19 July 2016

Accepted: 17 August 2016

*Correspondence:

Dr. Karthiga Prabhu J.,

E-mail: j.karthigaprabhu@gmail.com

Copyright: ( ) the author(s), publisher and licensee Medip Academy. This is an open-access article distributed under the terms of the Creative Commons Attribution Non-Commercial License, which permits unrestricted non-commercial use, distribution, and reproduction in any medium, provided the original work is properly cited.

\section{ABSTRACT}

Background: Generally, we would like to preserve ovaries during hysterectomy for benign conditions. Many of them come back with ovarian cysts and pain abdomen. Recently there were ten cases of residual ovaries requiring surgery during a year period which made us analyze these cases.

Methods: This retrospective descriptive analysis was conducted in SRM Medical College Hospital and Research Centre. Data about residual ovaries requiring surgery were retrieved from the medical records department and operation records and analyzed.

Results: There were ten cases of residual ovaries from January 2015 to December 2015 requiring surgery. In $70 \%$ of patients, residual ovary syndrome occurred within 5 years of hysterectomy. Majority $(80 \%)$ of them were following abdominal hysterectomy. The most common symptom among these patients was chronic pelvic pain. Pelvic adhesions were present in most of the cases. Follicular cyst and hemorrhagic corpus luteum were the commonest pathological findings in the residual ovaries (50\%). There were two cases of endometriotic cyst and a case of secondary malignant ovarian tumor with primary growth from stomach in a 40 year old woman for whom hysterectomy was performed five years ago for adenomyosis.

Conclusions: When the ovaries are preserved the woman should be properly counseled and should undergo periodic clinical and ultrasonographic follow-up.

Keywords: Residual ovaries, Signet ring cell carcinoma, Ovarian tumour, Endometriotic cysts, Haemorrhagic corpus luteum

\section{INTRODUCTION}

Generally, we would like to preserve ovaries during hysterectomy for benign conditions. Many of them come back with varied problems including ovarian masses requiring surgical intervention. ${ }^{1}$ Residual ovary syndrome is the condition in which an ovary that has previously been conserved, either develops an abnormal pathological process or causes symptoms necessitating its surgical removal. $^{2}$ Analysis of the histopathology of these ovarian masses will help us to review whether prophylactic oopherectomy will be beneficial in patients undergoing hysterectomy. Hence, the objective of our study is to analyze the pathology of adnexal masses requiring reoperation in women with prior hysterectomy.

\section{METHODS}

This retrospective descriptive study was conducted in SRM Medical College Hospital and Research Centre from January 2015 to December 2015. Data about the cases undergoing reoperation following hysterectomy 
were retrieved from the medical records department. Demographic data, previous indication for hysterectomy, mode of hysterectomy, time between hysterectomy and surgery for ovarian masses were noted. Histopathology report of the adnexal masses was also collected and frequencies of the various variables were determined.

\section{RESULTS}

There were 10 cases of residual ovaries requiring surgery during the study period. Majority of patients with residual ovaries $(60 \%)$ had undergone hysterectomy before the age of 40 years and in $70 \%$ of patients residual ovary syndrome occurred within 5 years after hysterectomy. Majority of them were following abdominal hysterectomy and the main indication for hysterectomy was fibroid uterus (Table 1).

Table 1: Clinical features.

\begin{tabular}{|ll|}
\hline Parameters & No. of cases (10) \\
\hline Chronic pelvic pain & 10 \\
\hline Abdominal mass & 1 \\
\hline $\begin{array}{l}\text { Pelvic mass on bimanual } \\
\text { examination }\end{array}$ & 5 \\
\hline
\end{tabular}

The most common symptom among these patients was chronic pelvic pain and bimanual pelvic mass was present in $60 \%$ of cases. Ultrasonography showed multiloculated cysts (Figure 1) in 4 patients and complex mass in 2 cases. $80 \%$ of the residual ovaries were less than $10 \mathrm{~cm}$.

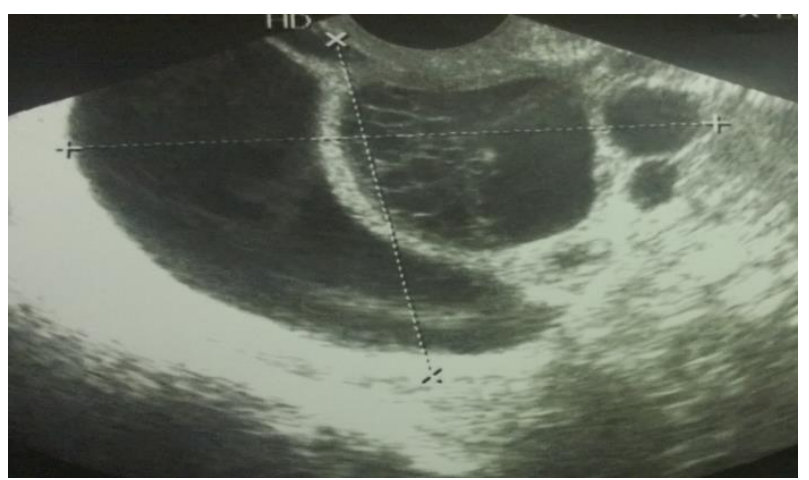

Figure 1: Ultrasonographic picture showing a post hysterectomy multiloculated cyst.

Figure 2 shows a multiloculated cyst at laparotomy. Pelvic adhesions were present in $60 \%$ of patients (Table 2). Follicular cyst and hemorrhagic corpus luteum (Figure 3) were the commonest pathological findings in the residual ovaries $(50 \%)$. Two patients had endometriotic cyst and one patient had secondary malignant ovarian tumor (Figure 3) with primary growth from stomach in a 40 year old woman for whom hysterectomy was performed five years ago for adenomyosis. As the tumour was inoperable gastric bypass was performed. One patient with endometriosis had bowel injury while dissecting adhesions and bowel resection with end-end anastomosis was performed.

Table 2: Previous surgery details.

\begin{tabular}{|ll|}
\hline Parameters & No. of cases \\
\hline Age at hysterectomy & \\
<40 years & 6 \\
40-50 years & 3 \\
$>50$ years & 1 \\
\hline Route of hysterectomy & \\
Abdominal & 8 \\
Vaginal & 2 \\
\hline Previous indication for & \\
hysterectomy & \\
Dysfunctional uterine bleeding & 2 \\
Fibroid & 5 \\
Adenomyosis & 2 \\
Prolapse & 1 \\
\hline Unilateral oopherectomy & 8 \\
\hline Hysterectomy performed when & \\
$<3$ years & 4 \\
3-5 years & 3 \\
\hline 5 years & 3 \\
\hline
\end{tabular}

Table 3: Ultrasound and operative findings.

\begin{tabular}{|ll|}
\hline Parameters & No. of cases \\
\hline Ultrasound findings & 3 \\
Simple cyst & 4 \\
Multiloculated cyst & 2 \\
Complex cyst & 1 \\
Heterogenous mass & \\
\hline Operative findings & \\
\hline Size of cyst & 4 \\
$<5$ cm & 4 \\
5-10 cm & 2 \\
$>10$ cm & 6 \\
\hline Pelvic adhesions & 7 \\
\hline Route of reoperation & 3 \\
Laparoscopy & \\
Laparotomy & 6 \\
\hline Surgery performed & 2 \\
Unilateral ovariotomy & 1 \\
Bilateral ovariotomy & 1 \\
Ovariotomy with gastric \\
bypass surgery \\
Ovariotomy + end to end \\
anastomosis + diverting \\
colostomy
\end{tabular}




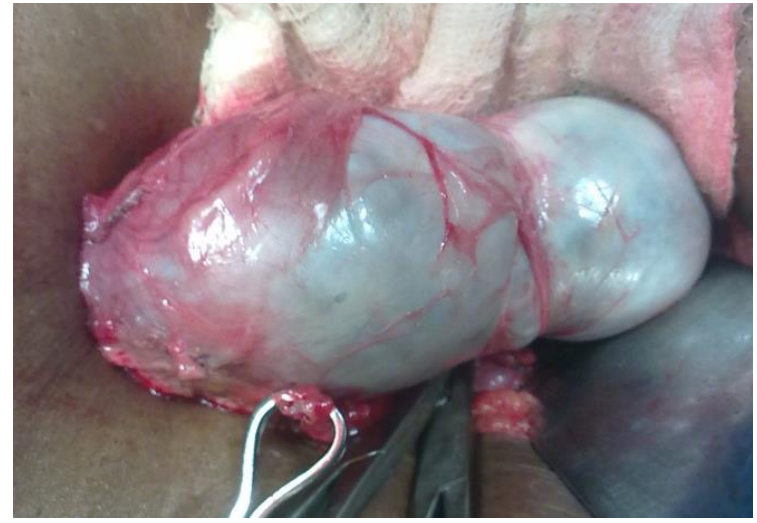

Figure 2: shows a post hysterectomy multiloculated cyst.

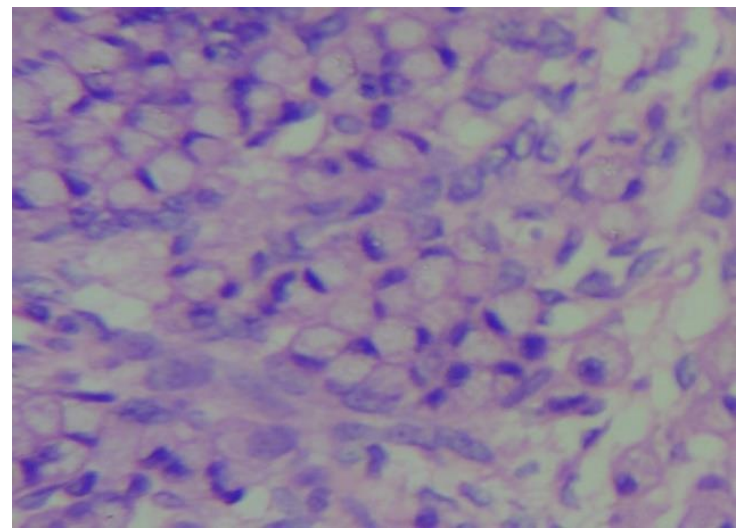

Figure 3: High power view of metastatic signet ring cell carcinoma of ovary (primary from stomach) $(\mathbf{H}$ \&E).

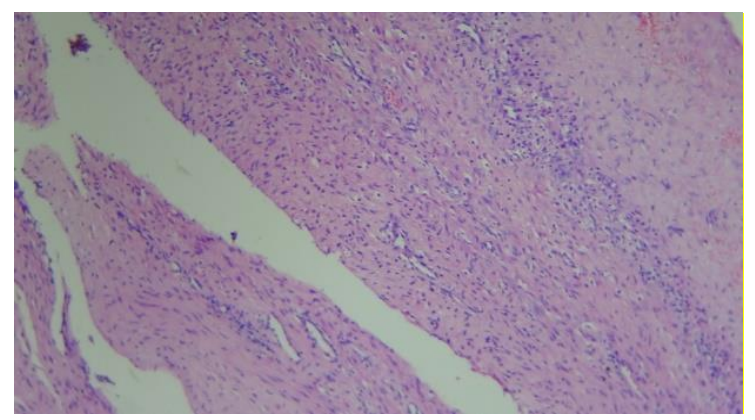

Figure 4: Low power view of haemorrhagic corpus luteum (H \&E).

\section{DISCUSSION}

Women with ovarian preservation are at risk for future oophorectomy. This risk ranged from $2.9 \%$ to $10.6 \% .^{2-4}$ In our study chronic pelvic pain was the main presenting symptom in all patients and pelvic mass was present in $60 \%$ of patients. According to Dekel et al recurrent or chronic pelvic pain $(71-77 \%)$, urinary tract disturbances $(33 \%)$, dyspareunia $(67 \%)$, pelvic mass on bimanual examination (14-25\%) were the usual presenting symptoms of residual ovaries. ${ }^{2}$ The interval between hysterectomy and reoperation for the residual adnexal disease syndrome has been reported between 4 months to 26 years. ${ }^{2,5}$ In the present study $70 \%$ had residual ovaries within 5 years after hysterectomy. $60 \%$ of patients with residual ovaries had hysterectomy before 40 years. Residual ovary syndrome was more common in younger women who underwent hysterectomy probably due to the longer ovarian function resulting in more functional ovarian pathology. Hwu et al has shown that the frequency of residual ovary syndrome was twice more common in women who had one ovary preserved rather than both $(7.6$ versus $3.6 \%) .{ }^{5}$ In our study with residual ovaries, $80 \%$ had undergone unilateral oopherectomy along with hysterectomy. In the present study functional cysts (follicular cyst and corpus luteal cyst) was the commonest histological finding. Endometriotic cyst was present in two patients. This maybe because of the persistence of the ovarian function following surgery. Signet ring cell carcinoma was present in one patient. In the study by Dekel et al, the histological findings reported were functional cysts, benign neoplasm and ovarian carcinoma in $50.7 \%, 42.6 \% \& 12.3 \%$ of cases, respectively.$^{2}$ In a retrospective analysis the incidence of malignant neoplasm in the residual ovaries was $3.0 \%$ depending on whether hysterectomy was performed before or after the age of 40 years. $^{6}$

In younger age group patients, use of progestogen may have a role in preventing and treating benign cyst formation. In a German study, probatory treatment with high-dosage progestogen (Depo-Provera) has made the residual ovarian cyst disappear completely in $71 \%$ of cases and pain completely in $39 \%$. Only in $8 \%$ the size of the residual ovarian cyst and in $20 \%$ the pain did not respond to treatment. ${ }^{7}$ Suppression of ovarian function by GnRH analogues may allow differentiation of pelvic pain caused by the residual ovary syndrome from other causes. $^{8}$

According to Holub et al, a number of factors such as age, primary histologic findings, smaller peritoneal trauma had a significant impact on difference in reoperation rate between vaginal, laparoscopic and abdominal hysterectomies in female patients with preserved adnexa. In a retrospective study, the reoperation rate was significantly different $(\mathrm{p}<0.006)$ based on the observed approaches to hysterectomy (Total abdominal hysterectomy $5.67 \%$, Vaginal Hysterectomy $0.69 \%$, Laparoscopic Hysterectomy 3.18\%). ${ }^{9}$

\section{CONCLUSION}

Due to physiologic ovarian function, benign cyst formation and hemorrhagic corpus luteum are the commonest findings in residual ovaries. The decision to perform oophorectomy at the time of hysterectomy for benign conditions should be individually based taking into consideration the patient's preference, age, and family risk factors. When the ovaries are preserved the woman should be properly counselled and should 
undergo periodic clinical and ultrasonographic follow up.

Funding: No funding sources

Conflict of interest: None declared

Ethical approval: Not required

\section{REFERENCES}

1. Shiber LD, Gregory EJ, Gaskins JT, Biscette SM. Adnexal masses requiring reoperation in women with previous hysterectomy with or without adnexectomy. Eur J Obstet Gynecol Reprod Biol. 2016;200:123-7.

2. Dekel A, Efrat Z, Orvieto R, Levy T, Dicker D, Gal $\mathrm{R}$, et al. The residual ovary syndrome: a 20-year experience. Eur J Obstet Gynecol Reprod Biol. 1996;68(1-2):159-64.

3. Casiano ER, Trabuco EC, Bharucha AE, Weaver AL, Schleck CD, Melton LJ, et al. Risk of oophorectomy after hysterectomy. Obstet Gynecol. 2013;121(5):1069-74.

4. ACOG. ACOG Practice Bulletin No. 89. Elective and risk-reducing salpingo-oophorectomy. Obstet Gynecol. 2008;111(1):231-41.

5. Hwu YM, Wu CH, Yang YC, Wang KG. The Residual ovary syndrome. Zhonghua Yi Xue Za Zhi (Taipei). 1989;43(5):335-40.

6. Christ JE, Lotze EC. The residual ovary syndrome. Obstet Gynecol. 1975;46(5):551-6.

7. Hauser GA. Residual ovary syndrome-significance of medical therapy. Geburtshilfe Frauenheilkd. 1980;40(1):17-24.

8. Carey MP, Slack MC. GnRH analogue in assessing chronic pelvic pain in women with residual ovaries. Br J Obstet Gynaecol. 1996;103(2):150-3.

9. Holub Z, Jandourek M, Jabor A, Kliment L, Wágnerová M. Does hysterectomy without salpingooophorectomy influence the reoperation rate for adnexal pathology? A retrospective study. Clin Exp Obstet Gynecol. 2000;27(2):109-12.

Cite this article as: Karthiga Prabhu J, Ramya S, Valli V, Muthulakshmi M. Analysis of adnexal masses requiring reoperation following hysterectomy. Int J Reprod Contracept Obstet Gynecol 2016;5:2952-5. 